American Journal of Pharmaceutical Education 2016; 80 (9) Article 152.

\title{
RESEARCH
}

\section{A Novel Mathematical Model for Determining Faculty Workload}

\author{
Leo R. Fitzpatrick, PhD, Carol Millette-Snodgrass, PharmD, Eman Atef, PhD \\ California Northstate University College of Pharmacy, Elk Grove, California \\ Submitted August 18, 2015; accepted November 20, 2015; published November 25, 2016.
}

Objective. To develop a mathematical model for determining faculty workload at a college of pharmacy with a team-based learning curriculum.

Methods. Using faculty provided data, our model calculated activity and weighted means in teaching, scholarship and service. Subsequently, these data were used to develop departmental and institutional workload models.

Results. For the pharmaceutical and biomedical sciences department, percent faculty activity mean values were greatest for service followed by teaching and scholarship. These values in the clinical sciences department were greatest for teaching followed by service and scholarship. Overall, the institutional workload model had the largest maximum faculty activity value for teaching, followed by service and then scholarship.

Conclusions. A novel faculty workload model proved to be effective in optimizing faculty workload within a college of pharmacy. Since the workload analysis, the faculty service commitment has been substantially changed, by reducing the number of committees at our institution. This type of workload analysis may particularly benefit colleges of pharmacy that employ a team based learning curriculum, with a large time commitment to teaching.

Keywords: faculty workload, mathematical model, pharmacy faculty, faculty retention

\section{INTRODUCTION}

Workload is a key factor in faculty satisfaction and retention at US pharmacy schools. ${ }^{1,2}$ Excessive workload was one of the top 2 reasons reported by faculty members for leaving an institution. ${ }^{1}$ Faculty workload is an especially important consideration at schools of pharmacy that use a team-based learning (TBL) curriculum, because TBL has been shown to increase faculty workload. ${ }^{3,4}$ There are only 2 published studies in which faculty workload was quantified using well-organized mathematical methods., ${ }^{5,6}$ One of these publications was a workload-related survey of 12 pharmacy schools. ${ }^{5}$ This survey did not include a comprehensive mathematical model for determining faculty workload, because only $40 \%$ of the respondents to the survey were unaware that a formula to measure workload existed at their institutions. ${ }^{5}$ Desselle et al developed a more sophisticated model for faculty workload. ${ }^{6}$ However, it was somewhat limited in format and scope in terms of representing an overall institutional mathematical workload model.

A faculty taskforce was formed in 2014 to more empirically quantify faculty workload at the California

Corresponding Author: Leo R. Fitzpatrick, Room 251, California Northstate University College of Pharmacy, 9700 West Taron Drive, Elk Grove, CA 95757. Tel: 916-686-8364. Fax: 916-686-8143. E-mail: lfitzpatrick@cnsu.edu
Northstate University College of Pharmacy. Using data gathered from 28 participating faculty members, a novel mathematical workload model was developed. ${ }^{7}$ Specifically, this workload model is dynamic in nature (ie, uses minimum and maximum activity values) to ultimately create a better faculty evaluation system. ${ }^{8}$

This manuscript will describe the mathematical methods used to create the departmental and institutional workload models at California Northstate University College of Pharmacy. We believe that this type of model may offer a new template for other academic/pharmacy institutions that are interested in doing a faculty workload analysis.

\section{METHODS}

The California Northstate University College of Pharmacy is located in Elk Grove, California. The College of Pharmacy consists of a Pharmaceutical and Biomedical Sciences Department and a Clinical Sciences Department. Our institution adopted a TBL-based curriculum in 2008. Nine faculty members from the Biomedical and Pharmaceutical Sciences Department and 21 faculty members from the Clinical Sciences Department were asked to participate in the analysis. This datagathering phase of the study took place from March 2014 to July of 2014. 


\section{American Journal of Pharmaceutical Education 2016; 80 (9) Article 152.}

All participating faculty members were asked to list their activities in the areas of teaching, institutional service, scholarship and professional development. Faculty members were not typically prompted, or given a checklist. The Clinical Sciences Department also provided activities within the area of clinical service. Activities were directly listed as supplied by faculty members unless there was clear overlap in an activity as determined via conversations between the lead author (LRF) and faculty members. The individual activities designated by faculty members were assigned a timeframe, which was typically expressed as hours per week. In certain instances, clinical faculty members provided their information in hours per semester or hours per clinical experience. These totals were then converted to hours per week based on a 16-week semester or a 6-week clinical experience, respectively.

To create a mathematical workload model, faculty activities (hours per week) were first converted to activity scores using the interval scale shown in Table 1. This scoring system allowed a minimum score of 0 (for 0 hours for an activity) up to a maximum score of 5 (for 46 to 50 hours for an activity).

Using GraphPad Prism 6 (Graph Pad Software, Inc, La Jolla, CA), a mean value was calculated for each applicable faculty activity score. Subsequently, weighted means were determined by multiplying the mean activity score by the number of faculty members engaging in that activity. The $95 \%$ confidence limits [CL] for the weighted means were also determined as part of the workload analysis. Weighted means and 95\% CL were determined for each faculty activity category (eg, teaching, service, scholarship, faculty development).

Total activity scores were calculated by multiplying the applicable weighted mean for an activity category by the number of activities in that category. In a similar fashion, the $95 \%$ CL for the appropriate total activity score were calculated by multiplying the upper and lower CL

Table 1. Interval Scale for Assigning Activity Scores to Faculty Activities

\begin{tabular}{lc}
\hline Hours per Week & Activity Score \\
\hline $0-5$ & 0.5 \\
$6-10$ & 1.0 \\
$11-15$ & 1.5 \\
$16-20$ & 2.0 \\
$21-25$ & 2.5 \\
$26-30$ & 3.0 \\
$31-35$ & 3.5 \\
$36-40$ & 4.0 \\
$41-45$ & 4.5 \\
$46-50$ & 5.0 \\
\hline
\end{tabular}

values by the number of activities. By adding the total activity scores from individual faculty categories, a global total activity score was determined from the data. This value was used in the final percent activity calculations for the applicable category.

The percent of total faculty activities for each department was calculated by dividing the category total activity scores by the global total activity score. In a similar fashion, the $95 \%$ CLs for the percent total faculty activities were determined by dividing the $95 \%$ CLs for the category activity scores by the global total activity scores.

The $95 \%$ CLs of the percent total activities were used to create the minimum and maximum values (or weights) for the departmental workload model. These types of values were recommended as part of a nonstatic faculty workload model described by Areola. ${ }^{8}$ Using this methodology, faculty workload models were created for both the Pharmaceutical and Biomedical Sciences and Clinical Sciences Departments.

The institutional model was created based on the 4 common activities from both departments (ie, teaching, service, scholarship and professional development $)^{8}$. The most absolute minimum and maximum values were determined from the 2 individual departmental workload models. $^{8}$

\section{RESULTS}

The study participation rate was $89 \%$ (8/9) for Pharmaceutical and Biomedical Sciences faculty members and $87 \%$ (18/21) for Clinical Sciences faculty members. Thus, the overall participation rate was $87 \%(26 / 30)$.

The Pharmaceutical and Biomedical Sciences faculty identified 4 major areas for their activities: service, teaching, scholarship, and professional development. In contrast, the Clinical Department identified 5 major activity areas. The Clinical Department identified these same four areas, as well as a fifth area, clinical practice.

\section{Faculty Activities Summary}

For the Pharmaceutical and Biomedical Sciences Department, the reported number of faculty activities in each activity area was as follows: service, 43; teaching, 21; scholarship, 15; and professional development, 5. Thus, a total of 84 distinct activities were reported by the 8 participating faculty members from this department. For the Clinical Sciences Department, the reported number of faculty activities in each area was as follows: teaching, 15; service, 13; scholarship, 11; professional development, 26; and clinical practice, 4 . Thus, a total of 69 distinct activities were reported by the 18 participating faculty members. 


\section{American Journal of Pharmaceutical Education 2016; 80 (9) Article 152.}

The teaching activity data from the Clinical Sciences and Pharmaceutical and Biomedical Sciences departments are shown in Figures 1 and 2, respectively. As shown in Figure 1, all mean teaching activity scores were $\leq 1$, suggesting faculty members typically spent less than 10 hours per week on these individual activities. Interestingly, weighted means ranged from 6 (classroom-based elective course activity) to 14 (classroom-based course activity). The data in Figure 2 illustrates that most mean teaching activity scores were $\leq 2$, suggesting faculty members typically spent less than 20 hours per week on these individual activities. Pharmaceutical and Biomedical Sciences faculty members, who prepared handouts for TBL classes, spent approximately 15 to 20 hours per week on this activity. Weighted means ranged from $<1$ (e.g., conference calls) to 15 (preparation of course handouts).

Using collected data, weighted means were also generated in a similar fashion for other main areas of faculty activity. At the time of the workload analysis, 14/18 clinical faculty members were engaged in practice site activities. The mean practice site score was 1.75 , which equals 17.5 hours per week, using our interval scale shown in Table 1. Four responding faculty members did not have a practice site at the time of the workload analysis. Because there were only 14 responders, the weighted mean for this activity became $1.75 \times 14=24.5$.

These weighted means and $95 \%$ CL were used to develop departmental workload models, as described above. The number of faculty responders was typically

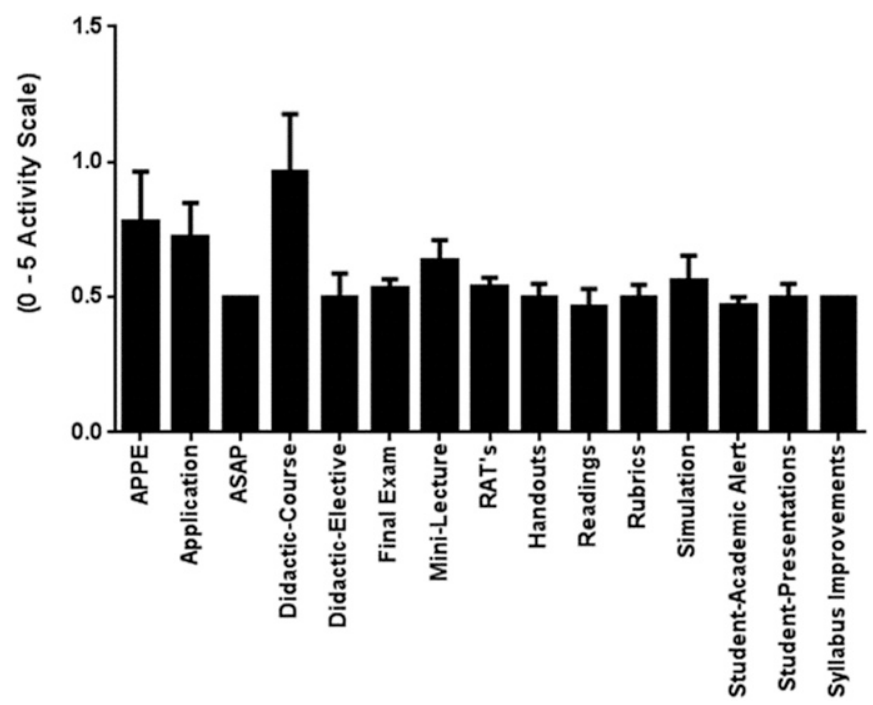

Figure 1. Clinical Sciences Department Teaching Activities. A total of 15 activities were identified by faculty, and all were used in the analysis. Abbreviations: APPE is Advanced Pharmacy Practice Experience; ASAP is an internal acronym for the Sakai learning management system; RAT's are Readiness Assurance Tests.

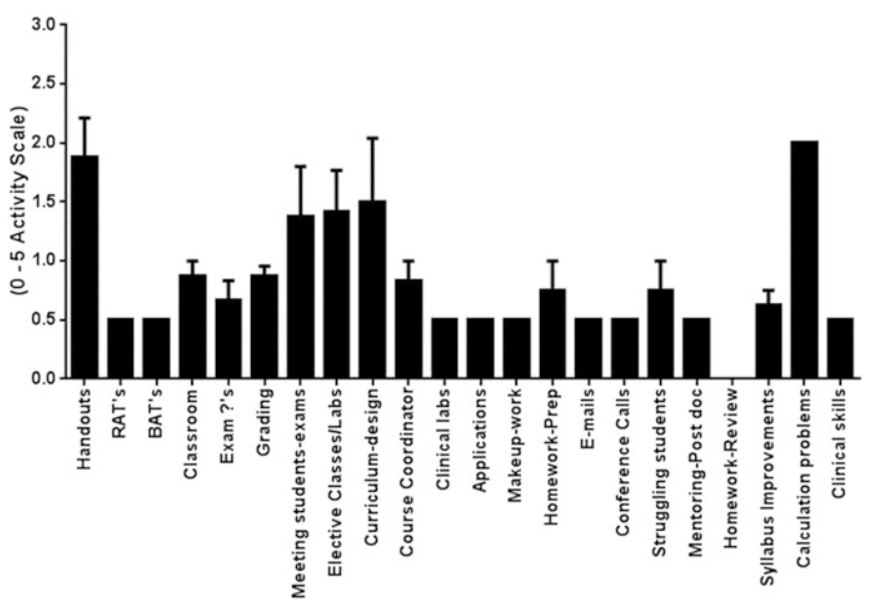

Figure 2. Pharmaceutical and Biomedical Sciences Department Teaching Activities. A total of 22 activities were identified by faculty, and 21 were used in the analysis. Insufficient data was received for the homework review activity to generate a mean activity score. Abbreviations: RAT's are Readiness Assurance Tests; BAT's are Basic Application Tasks.

greater for the Clinical Sciences Department than the Pharmaceutical and Biomedical Sciences department. This factor resulted in mostly larger weighted mean values for the Clinical Sciences Department (compare Tables 2 and 3). The exception was for professional development, for which the number of clinical faculty responders was $\leq 4$, resulting in a low weighted mean value (Table 3 ).

Total activity scores and percent total activities were determined as described in the methods section. Using these data, individual departmental workload analyses tables were created for the Pharmaceutical and Biomedical Sciences Department (Table 2) and the Clinical Sciences Department (Table 3). For the Pharmaceutical and Biomedical Sciences Department, calculated mean activity values were: service, 39\%; teaching, 34\%; scholarship, 22\%; and professional development, $5 \%$. For the Clinical Sciences Department, mean activity values were: teaching, 39\%; service, $24 \%$; clinical practice, $18 \%$; scholarship, 14\%; and professional development, $5 \%$.

Subsequently, using the data from Tables 2 and 3, workload models were created for the 2 departments, as generally recommended by Arreola. ${ }^{8}$ These departmental workload models are shown in Table 4 (Pharmaceutical and Biomedical Sciences) and Table 5 (Clinical Sciences). For Pharmaceutical and Biomedical Sciences faculty members, minimum and maximum values were higher for teaching and service than for scholarship and professional development (Table 4). A similar trend was noted for Clinical Sciences faculty members (Table 5).

The ultimate goal of the faculty workload process described above was to develop an institutional workload 


\section{American Journal of Pharmaceutical Education 2016; 80 (9) Article 152.}

Table 2. Pharmaceutical and Biomedical Sciences Department Workload Analysis

\begin{tabular}{lcccc}
\hline & $\begin{array}{c}\text { Weighted Mean } \\
\text { [95\% C.L.] }\end{array}$ & Activities, No. & Total Activity Score & \multicolumn{2}{c}{ Total Activity, \% } \\
[95\% C.L.] & [95\% C.L.] \\
\hline Service & $2[1.4-2.3]$ & 43 & $79[62-97]$ & Mean $=39 \%[30-49]$ \\
Teaching & $3[2-5]$ & 21 & $70[35-105]$ & Mean $=34 \%[17-52]$ \\
Scholarship & $3[2-4]$ & 15 & $44[27-62]$ & Mean $=22 \%[13-30]$ \\
Professional Development & $2[0-5]$ & 9 & $11[0-23]$ & Mean $=5 \%[0-11]$ \\
TOTAL & & 84 & 204 & $100 \%$ \\
\hline
\end{tabular}

model for the California Northstate University College of Pharmacy (Table 6). Minimum and maximum values were higher for teaching and service (range: $17 \%$ to $52 \%$ ) than for scholarship and professional development (range: 0 to $30 \%$ ).

\section{DISCUSSION}

Colleges of pharmacy faculty workload models, which have used specific mathematical techniques, are not prominent in the relevant literature. Previously, Desselle et al assessed faculty activities in teaching and scholarship. ${ }^{5}$ Their methods involved the calculation of adjusted mean and median values for these faculty activities. Faculty service activities were not specifically reported in this manuscript. Moreover, departmental and institutional workload models were not determined in this previous paper. ${ }^{5}$ However, these results did provide an impetus for developing a new faculty workload model at our institution.

Being a primarily TBL institution, we expected that some reported activities (eg, readiness assurance tests [RATs], and basic application tasks [BATs]) would be different than other more common teaching activities (Figures 1 and 2). As suggested in previous publications, labor intensive TBL teaching-related activities include curriculum design and the preparation of class handouts. ${ }^{3,4}$ The faculty workload analysis has reinforced the concept from the relevant literature that new faculty course coordinators (within the first year of employment at our college of pharmacy) need more time to prepare for TBL-based classes than faculty members with more experience in TBL or faculty members not using a TBL curriculum. ${ }^{3,4,10}$
Faculty service results showed time-consuming weighted/rounded mean values of 8 (Pharmaceutical \& Biomedical Sciences Department) and 12 (Clinical Sciences Department), for committee participation. In response to these service-related results, the administration at our institution has begun to optimize faculty workload by reducing committee involvement. Specifically, since the workload analysis, 8 committees have been abolished. Prior to the workload analysis, some faculty members were serving on as many as 9 committees. Faculty participation on committees was reduced to about 5 committees in 2014 and 3 in 2015.

Within the Clinical Sciences Department, the highest weighted mean activity value (24.5) was for practice site commitments. This is a fundamental activity and important function of clinical faculty members at our College of Pharmacy.

On average, members of both departments at California Northstate University College of Pharmacy spent only $5 \%$ of their time (Tables 2 and 3 ) on professional development (eg, attending conferences or scientific meetings). Interestingly, there was a wide discrepancy in the numbers of self-reported faculty activities in this category. The Pharmaceutical and Biomedical Sciences Department reported 9 activities in this category (Table 2), while the Clinical Sciences Department reported 26 activities of this ilk. The differences seem to relate to some clinical faculty members reporting activities (eg, consulting, poster presentations) which may conceivably fall into other categories (like scholarship). Nevertheless, the corresponding weighted mean activity values were low $(\leq 1)$, and likely would not significantly change the departmental workload model.

Table 3. Clinical Sciences Department Workload Analysis

\begin{tabular}{|c|c|c|c|c|}
\hline Activity & $\begin{array}{c}\text { Weighted Mean } \\
\text { [95\% C.L.] }\end{array}$ & Activities, No. & $\begin{array}{c}\text { Total Activity Score } \\
\text { [95\% C.L.] }\end{array}$ & $\begin{array}{c}\text { Total Activity, \% } \\
\text { [95\% C.L.] }\end{array}$ \\
\hline Teaching & $9[8-10]$ & 15 & 131 [113 - 149] & Mean $=39 \%[34-44]$ \\
\hline Service & $6[4-8]$ & 13 & $81[58-104]$ & Mean $=24 \%[17-31]$ \\
\hline Clinical Practice & $15[1.88-27.63]$ & 4 & $59[8-111]$ & Mean $=18 \%[2-33]$ \\
\hline Scholarship & $4[3-6]$ & 11 & $47[28-66]$ & Mean $=14 \%[8-20]$ \\
\hline Professional Development & $0.7[0.5-0.9]$ & 26 & $19[14-23]$ & Mean = 5\% [4 - 7] \\
\hline TOTAL & & 69 & 337 & $100 \%$ \\
\hline
\end{tabular}




\section{American Journal of Pharmaceutical Education 2016; 80 (9) Article 152.}

Table 4. Pharmaceutical and Biomedical Sciences Department Workload Model

\begin{tabular}{lcc}
\hline Faculty Role & $\begin{array}{c}\text { Minimum } \\
\text { Value/Weight, \% }\end{array}$ & $\begin{array}{c}\text { Maximum } \\
\text { Value/Weight, \% }\end{array}$ \\
\hline Teaching & 17 & 52 \\
Service & 30 & 48 \\
Scholarship & 13 & 30 \\
Professional & 0 & 11 \\
$\quad$ Development & & \\
\hline
\end{tabular}

Data reported on scholarship activities revealed that pharmaceutical and biomedical sciences faculty members spent most of their time for this activity conducting experiments in the laboratory (weighted mean value $=8$ ), while clinical sciences faculty members spent most of their time on data evaluation (weighted mean value $=7$ ). These results likely reflect the differences in research and scholarship activities as well as in methods used within the 2 departments.

The departmental workload analyses (Tables 2 and 3) suggest that faculty members at our institution are spending on average only $14 \%$ to $22 \%$ of their time on scholarship. These results are not entirely surprising based on the current TBL curriculum at our institution, as well as previous results reported in the relevant literature. ${ }^{2-4,9}$

Of note, some cited reasons for high faculty turnover among pharmacy faculty members are the excessive workload, desire for change, and poor salary. ${ }^{1}$ Specifically, faculty retention has been related to whether the time for research activities is compromised as a result of a high teaching or service load. ${ }^{2}$ Therefore, departmental chairs (and other pertinent administrators) at other pharmacy schools may find our workload analysis model useful in making decisions such, as shifting faculty members into categories that are best suited to their talents and productivity. For example, individual faculty members who excel in a certain activity (eg, scholarship) could be slotted within the overall range of minimum and maximum activity values for a department or the institution (Tables 4-6). Such faculty members could spend up to

Table 5. Clinical Sciences Department Workload Model

\begin{tabular}{lcc}
\hline Faculty Role & $\begin{array}{c}\text { Minimum } \\
\text { Value/Weight, } \%\end{array}$ & $\begin{array}{c}\text { Maximum } \\
\text { Value/Weight, \% }\end{array}$ \\
\hline Teaching & 34 & 44 \\
Service & 17 & 31 \\
Clinical Service & 2 & 33 \\
Scholarship & 8 & 20 \\
Professional & 4 & 7 \\
$\quad$ Development & & \\
\hline
\end{tabular}

Table 6. College of Pharmacy Institutional Workload Model

\begin{tabular}{lcc}
\hline Faculty Role & $\begin{array}{c}\text { Minimum } \\
\text { Value/Weight, \% }\end{array}$ & $\begin{array}{c}\text { Maximum } \\
\text { Value/Weight, \% }\end{array}$ \\
\hline Teaching & 17 & 52 \\
Service & 17 & 48 \\
Scholarship & 8 & 30 \\
Professional & 0 & 11 \\
$\quad$ Development & & \\
\hline
\end{tabular}

$30 \%$ of their time on research or scholarship. Using these tables, faculty satisfaction should be increased, while still maintaining equity within the workload constraints of the department and/or institution as a whole. Intuitively, this type of workload-driven exercise should enhance faculty retention at the institution. ${ }^{8}$

One possible solution to this "scholarship dilemma" might be to use some service activity (such as workload analysis) as a scholarship activity, similar to the idea of scholarly teaching activities. ${ }^{2,7,10-11}$ This type of scholarly approach would offer faculty members an opportunity to advance in scholarly endeavors, and not just engage in a time consuming "must do" type of activity.

The main goal of this manuscript was to propose a model for use by other pharmacy or professional schools that are interested in doing a faculty workload analysis. We recognize that a workload analysis is dynamic in nature and therefore a constantly evolving process. $^{8}$ Therefore, it will be influenced by factors such as the prevalence of new faculty members, as well as the type of curriculum used by the institution. In this regard, the data captured in this paper represent only a snapshot of faculty workload at our college during 2014. Nevertheless, the mathematical principles of the model are useful for future workload analyses. We recommend that institutions do a new workload analysis at least every 2 years. This frequency is needed to capture the most recent faculty workload efforts, as well as to determine whether previous workload analyses influenced changes at the institution. ${ }^{7,8}$

Arreola has provided a mathematical check for the type of "dynamic mathematical workload model" used in this paper. ${ }^{8}$ Ideally any combination of maximum and remaining minimum values for a faculty activity should be in the range of $65 \%$ to $100 \%$ and cannot exceed $100 \%{ }^{8}$ In this regard, our departmental and institutional workload models (Tables 4-6) generally meet these criteria. For example, in Table 4, the teaching maximum value $(52 \%)+$ service minimum value $(30 \%)+$ scholarship minimum value $(13 \%)+$ professional development minimum value $(0 \%)=95 \%$ (ie, less than $100 \%$ ).

Arreola also emphasizes that a "static faculty workload model" (using just mean activity values) does not 


\section{American Journal of Pharmaceutical Education 2016; 80 (9) Article 152.}

adequately reflect the diversity of faculty responsibilities at an institution. ${ }^{8}$ Therefore, a dynamic faculty workload model should be employed (using minimum and maximum weight values) to create a fair system for effectively utilizing the talents of faculty members, as well as creating a better faculty evaluation system. ${ }^{8}$

\section{CONCLUSION}

We created a novel mathematical model for determining faculty workload at the California Northstate University College of Pharmacy. We believe that this workload model (or some version thereof) may be useful for other schools of pharmacy in determining faculty workload parameters at their institutions.

\section{ACKNOWLEDGMENTS}

We would like to acknowledge the encouragement of Dr. Shane Desselle during the implementation of the faculty workload process.

\section{REFERENCES}

1. Conklin MH, Desselle SP. Job turnover intentions among pharmacy faculty. Am J Pharm Educ. 2007;71(14):Article 62. 2. Surratt CK, Kamal KM Widfong PLD. Research funding expectations as a function of faculty teaching/administrative workload. Res Social Adm Pharm. 2011;7(2):192-201.
3. Allen RE, Copeland J, Franks AS, et al. Team-based learning in US colleges and schools of pharmacy. Am J Pharm Educ. 2013;77(6): Article 115.

4. Conway SE, Johnson JL, Ripley TL. Integration of team-based learning strategies into a cardiovascular model. Am J Pharm Educ. 2010;74(2):Article 35.

5. Desselle SP, Mattei TJ, Vanderveen RP. Identifying and weighting teaching and scholarship activities among faculty members. Am J Pharm Educ. 2004;68(4):Article 90.

6. Wilborn TW, Timpe EM, Wu-Pong S, et al. Factors influencing faculty perceptions of teaching workload. Curr Pharm TeachLearn. 2013;5(1):9-13.

7. Fitzpatrick LR, Snodgrass CM, Atef E, Desselle S. A novel mathematical model for determining faculty workload at California Northstate University College of Pharmacy. 2015 AACP meeting, National Harbor, MD, poster presentation \#51.

8. Arreola RA. Developing a Comprehensive Faculty Evaluation System. 3rd ed. San Francisco, CA: Anker Publishing Inc. (Imprint of John Wiley \& Sons); 2007.

9. Kebodeaux CD, Vouri SM, Hurd PD. Team-based learning (TBL): an argument for faculty's evaluation. Innov Pharm. 2014;5(2):Article 152.

10. Smesny AL, Williams JS, Brazeau GA, Weber RJ, Matthews HW, Das SK. Barriers to scholarship in dentistry, nursing and pharmacy practice faculty. Am J Pharm Educ. 2007;71(5): Article 91.

11. Gubbins PO. The scholarship of teaching and learning: an opportunity for clinical faculty members in academic pharmacy and other health care professions to develop a program of scholarship. Int'l J Scholar Teach Learn. 2014;8(1):Article 3. 